
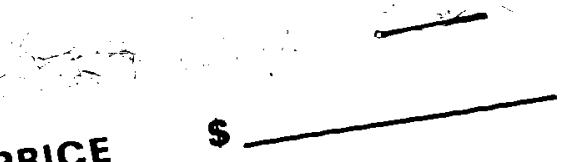

PREPRINT

GPO PRICE

CFSTI PRICE(S) \$

Hard copy $(\mathrm{HC})$ Microfiche (MF) 


\title{
FEASIBILITY OF DETERMINING ATMOSPHERIC OZONE FROM OUTGOING INFRARED ENERGY
}

\author{
C. Prabhakara*
}

May 1968

\section{GODDARD SPACE FLIGHT CENTER Greenbelt, Maryland}

* Goddard Institute for Space Studies, New York and Goddard Space Flight Center, GreenbeIt. 


\title{
PRECEDING PAGE BLANK NOT FILMED.
}

\author{
FEASIBILITY OF DETERMINING ATMOSPHERIC OZONE \\ FROM OUTGOING INFRARED ENERGY \\ C. Prabhakara
}

\begin{abstract}
The high resolution $\left(5 \mathrm{~cm}^{-1}\right)$ measurements of the outgoing infrared energy in the region of the $9.6 \mu$ ozone band offer a means of determining the vertical distribution and total amount of ozone in the earth's atmosphere. With the application of radiative transfer theory and perturbation technique a method is developed to deduce such information. The method hinges on a two parametric representation of the ozone distribution in the earth's atmosphere.

An error analysis based on four case studies is presented to show how well the atmospheric ozone could be determined. It is found that a small error in radiance value is magnified considerably in the infer eed atmospheric ozone.
\end{abstract}




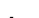


PRECEDING PAGE BLANK NOT FLMED.

CONTENTS

$\underline{\text { Page }}$

Abstract.................. iii

INTRODUCTION $\ldots \ldots \ldots \ldots \ldots \ldots \ldots \ldots \ldots$

MODEL OF THE ATMOSPHERIC OZONE

DISTRIBUTION $\ldots \ldots \ldots \ldots \ldots \ldots \ldots \ldots \ldots$

THEORY................... 5

TRANSMISSION FUNCTION............ 7

DISCUSSION OF RESULTS .............. 10

ACKNOWLEDGMENTS . . . . . . . . . . 15

References .................. 16 


\section{INTRODUCTION}

Atmospheric ozone is photochemically produced by solar near ultraviolet radiation. The global distribution of this gas as a function of latitude and season can reveal the stratospheric circulation, and coupling between the troposphere and stratosphere. Day to day changes in the weather are also reflected in the ozone variations. Thus it appears that a method of indirectly obtaining the atmospheric ozone from satellite borne radiation sensors could be very useful.

The problem of indirectly determining the vertical distribution of temperature and water vapor in the earth's atmosphere from remote radiation sensors has been studied by several investigators (see Wark and Fleming, 1966 and also for a review see Conrath, 1968). Such investigations were concerned with the infrared spectral regions of the $15 \mu \mathrm{CO}_{2}$ band, and the water vapor $6.3 \mu$ vibrationrotation and $20 \mu$ rotation bands. However in addition to these bands the IRIS (Infrared Interferometer Spectrometer) spectrum $\left(5 \mathrm{~cm}^{-1}\right.$ resolution), obtained at Palestine, Texas, shown in Fig. 1 reveals marked spectral structure in the region of $9.6 \mu$ ozone band. This feature present in observed spectrum prompted the present investigation to indirectly determine the atmospheric ozone.

The narrow (about $1.5 \mu$ wide) $9.6 \mu$ ozone band in such emission spectrum of the earth and atmosphere is influenced by the water vapor absorption in the so called 'window' region extending from 8 to $12 \mu$. So it is necessary to know the distribution of water vapor in the atmosphere in order to interpret the spectrum in the 9.6 i $i$ region. Although in principle it is nossible to determine the distribution of water vapor, temperature and ozone indirectly from the radiation 
measurements we have not attempted to do so in this preliminary study. Instead, the distribution of ozone alone is determined from the spectrum when the water vapor and temperature distributions are known.

Earlier studies which attempted to determine the atmospheric ozone from ground based measurements of the emission spectrum of ozone in the $9.6 \mu$ region were not encouraging (see for e.g., Dave et al., 1963). However some disadvantages encountered in interpreting the atmospheric emission spectra when measured at ground may not be encountered when the spectrum is obtained from space.

With this view in mind we have computed spectra for several stations at which soundings of temperature, water vapor and ozone were available. These synthetic spectra were then subjected to an inversion procedure to deduce the ozone distribution. The inversion procedure adopted here depends on a two parameter model for describing the ozone distribution. Such a model representation is arrived at from broad based climatological features of the atmospheric ozone.

The feasibility of determining atmospheric ozone is then demonstrated from an error analysis of four case studies. A small finite error in radiance is magnified to a large error in the inferred atmospheric ozone content. The magnification of error is different for each case and is intolerably large under certain circumstances. 
On account of several inadequacies of data pertaining to the absorption coefficients and atmospheric temperature and water vapor sounding we could not perform an inversion and obtain the ozone distribution for Palestine, Texas. However a reasonable match of the spectrum is shown to illustrate the general soundness of the scheme.

This investigation is intended to be a pilot study of this problem. Several spectra will be available from the forthcoming meteorological satellites which may be analysed with the help of the findings from this study.

\section{MODEL OF THE ATMOSPHERIC OZONE DISTRIBUTION}

The atmospheric ozone is observed to change appreciably from day to day below about $25 \mathrm{~km}$. At higher elevations, where photochemical equilibrium is restored in a day or less, ozone changes are systematic and follow a sea sonal variation (Dütsch, 1963). In Fig. 2 the mean meridional distribution of ozone for spring and fall are shown (after Hering and Borden, 1965, a). Some significant features, concerning the vertical ozone distribution, can be deduced from these meridional cross sections. The pronounced ozone maximum in the stratosphere is present at all latitudes. The position of ozone maximum which is at about $24 \mathrm{~km}$ at low latitudes drops to lower altitudes as the north pole is approached. Also the rather sharp maximum present at low latitudes is replaced by a considerably broad one at high latitudes. The position of the tropopause as a function of latitude has a strong influence on the meridional distribution of ozone. The strong stratification that is present in the stratosphere is replaced by a very 
weak structure in the troposphere. On a further examination of several ozone soundings one can observe that the tropopause in the tropical latitudes in all seasons marks the level of transition from strong stratospheric to weak tropospheric structure in ozone. On the other hand at middle and high latitudes the tropopause has such significance only in summer and fall. During winter and spring such transition takes place at a level 3 to $4 \mathrm{~km}$ below the tropopause height.

With these climatological features a model of the distribution of ozone is made involving minimum number of parameters to describe it. Photochemical equilibrium distribution is assumed above some high altitude $Z_{1},(\sim 30 \mathrm{~km})$. Further down from the level $Z_{1}$, to the tropopause height, $Z_{2}$, a Gaussian distribution, which can simulate the pronounced maximum is adopted. Then in the troposphere the ozone concentration is assumed constant having a value equal to that obtained at $Z_{2}$, the tropopause height.

Let the Gaussian distribution describing the ozone variation between $Z_{1}$ and $\mathrm{Z}_{2}$ be given by

$$
O_{3}(Z)=O_{3}\left(z_{m}\right) \exp -\left[\frac{z-Z_{m}}{h}\right]^{2}
$$

where $O_{3}(Z)$ represents the ozone concentration at any height $Z,\left(Z_{1}>Z>Z_{2}\right)$, and $\mathrm{O}_{3}\left(Z_{\mathrm{m}}\right)$ is the ozone concentration maximum at the height $Z_{\mathrm{m}} \cdot \mathrm{h}$ is a measure of the dispersion of ozone about the height $Z_{\mathrm{m}}$. 
Now applying Equation (1) at the selected high level $z_{1}$, where $o_{3}\left(z_{1}\right)$ is assumed from Photochemical equilibrium, we have

$$
o_{3}\left(Z_{1}\right)=o_{3}\left(Z_{m}\right) \exp -\left[\frac{Z_{1}-Z_{m}}{h}\right]^{2}
$$

From Equations (1) and (2) $\mathrm{O}_{3}(Z)$ may be eliminated to yield

$$
o_{3}(Z)=O_{3}\left(Z_{1}\right) \exp \left[\frac{Z_{1}-Z_{m}}{h}\right]^{2} \exp -\left[\frac{Z-Z_{m}}{h}\right]^{2}
$$

Equation (3) describes ozone distribution, in the height region $Z_{1}$ to $Z_{2}$, in terms of two unknowns $Z_{\mathrm{m}}$ and $h$. This is essentially the two parameter representation.

\section{THEORY}

We know from radiative transfer theory that intensity $I_{\nu}$, of radiation at frequency $\nu$, upwelling from the earth's atmosphere is given by the equation (see for e.g., Elsasser, 1960)

$$
I_{\nu}=B_{\nu}\left(T_{0}\right) \tau_{\nu}(0)+\int_{\tau_{\nu}(0)}^{1} B_{\nu}\left(T_{z}\right) d \tau_{\nu}(Z)
$$

where

$\mathrm{B}_{\nu}$ is the Plank intensity,

$T_{0}$ and $T_{z}$ are the absolute temperatures at the ground and any height $Z$,

$\tau_{\nu}(0)$ and $\tau_{\nu}(Z)$ are the transmissions from ground and any level $Z$ to top of the atmosphere. 
The Equation (4), which forms the basis of all indirect methods or 'inversions,' is applied to small but finite, $5 \mathrm{~cm}^{-1}$ wide (to correspond to IRIS resolution), spectral intervals of the emission spectrum at $9.6 \mu$ region. As the $9.6 \mu$ band of ozone is about $150 \mathrm{~cm}^{-1}$ wide we may think of having about 30 such useful spectral intervals yielding as many independent pieces of information. However in practice we find that only two independent pieces of information can be elicited. This point will be elaborated in the discussion of the results.

The transmission $\tau_{\nu}$ in the $9.6 \mu$ region is influenced by both water vapor and ozone. So the effective transmission is given by

$$
\tau_{\nu}=\left(\tau_{\mathrm{H}_{2} \mathrm{O}} \cdot \tau_{\mathrm{O}_{3}}\right)_{\nu}
$$

where $\tau_{\mathrm{H}_{2} \mathrm{O}}$ and $\tau_{\mathrm{O}_{3}}$ are the transmissions of water vapor and ozone.

Let us choose two spectral intervals labled 1 and 2 , in the $9.6 \mu$ band, for which the upwelling intensities may be written as

$$
\begin{aligned}
& I_{1}=B_{1}\left(T_{0}\right) \tau_{1}(0)+\int B_{1}\left(T_{z}\right) d \tau_{1}(Z) \\
& I_{2}=B_{2}\left(T_{0}\right) \tau_{2}(0)+\int B_{2}\left(T_{z}\right) d \tau_{2}(Z)
\end{aligned}
$$

Since we are assuming the vertical soundings of temperature and water vapor we need to solve for the two parameters describing the vertical ozone distribution from Equations (6) and (7). The information pertaining to ozone is contained in the transmission functions $\tau_{1}$ and $\tau_{2}$. 
Let us suppose a small increment $\delta I$ in the intensity be due to a small increment $\delta Z_{\mathrm{m}}$ in the position of ozone maximum and a small increment $\delta \mathrm{h}$ in the dispersion. We may express such relationships by the equations

$$
\delta I_{1}=\frac{\partial I_{1}}{\partial Z_{m}} \delta Z_{m}+\frac{\partial I_{1}}{\partial h} \delta h
$$

and

$$
\delta \mathrm{I}_{2}=\frac{\partial \mathrm{I}_{2}}{\partial \mathrm{Z}_{\mathrm{m}}} \delta \mathbf{Z}_{\mathrm{m}}+\frac{\partial \mathrm{I}_{2}}{\partial \mathrm{h}} \delta \mathrm{h}
$$

The above simultaneous equations may be used to correct, by an iteration procedure, some initial guess for $Z_{\mathrm{m}}$ and $\mathrm{h}$ and eventually obtain correct values of these parameters, describing the ozone distribution, that yield the desired intensities $I_{1}$ and $I_{2}$. This is in essence the perturbation procedure used here.

\section{TRANSMISSION FUNCTION}

Based upon several earlier studies Möller and Raschke (1963) have presented a method of obtaining the transmission function for the water vapor in the $8-12 \mu$ region. This method is adopted in the present study.

The transmission function for ozone is taken from a study of Walshaw (1954), where he has investigated the $9.6 \mu$ band with a resolution of $6.5 \mathrm{~cm}^{-1}$. Walshaw has fitted the transmissio oy means of a statistical band model with allowance for a 'mòdulated contour' for the band (see Goody, 1964, a). The transmission 
function is given by

$$
\left.\begin{array}{l}
\frac{\operatorname{sinh~} \mathrm{k}_{\nu}{ }^{1 / 2} \mathrm{x}_{\nu}}{\mathrm{k}_{\nu}{ }^{1 / 2} \mathrm{x}_{\nu}} \text { when } \mathrm{k}_{\nu}>0 \\
\frac{\sin \left|\mathrm{k}_{\nu}\right|^{1 / 2} \mathrm{x}_{\nu}}{\left|\mathrm{k}_{\nu}\right|^{1 / 2} \mathrm{x}_{\nu}} \text { when } \mathrm{k}_{\nu}<0
\end{array}\right\}
$$

where

$$
\mathbf{X}_{\nu}=\left[\frac{\sigma_{\nu} \mathrm{m}}{\delta}\left(1+\frac{\sigma_{\nu} \mathrm{m}}{\pi a}\right)^{-1 / 2}\right]
$$

$\sigma_{\nu}$ is the mean line strength*

$a$ is the mean line half width

$\delta$ is the mean line spacing

$m$ is the path length of the absorbing gas

$\mathrm{k}_{\nu}$ is an emperically determined constant as a function of $\nu$ to get the best fit to the experimental measurements.

The above relationship is based on the assumption of exponential intensity distribution of spectral lines.

Walshaw's measurements were made for homogeneous paths in the laboratory while in the atmosphere we do not obtain such homogeneity conditions as the absorbing gas is distributed along a strongly varying pressure path. The variation

*All the parameters $\sigma_{\nu}, \alpha, \delta$ and $\mathbf{k}_{\nu}$ are obtained from Walshaw (1954). However according to Walshaw (1957) $\sigma$ was multiplied by 1.30 . 
of temperature along the path though present in the earth's atmosphere is never as pronounced. To take into account such inhomogeneous conditions, the CurtisGodson approximation is commonly used. This approximation is shown to be quite inadequate for the atmospheric ozone by Walshaw and Rodgers (1963) amongst others. It is possible to incorporate such inhomogeneous conditions and obtain radiative transfer without any approximation in a single spectral line (see for e.g., Hitschfeld and Houghton, 1961). Now the transmission $\tau^{\prime}$ in a spectral interval, large compared to a line, may be expressed in terms of the average absorption in one line provided we adopt a statistical model, for the transmission function, which assumes lines of equal intensity but with random position (Goody, 1964, b). Thus we have

$$
\tau^{\prime}=\exp -\frac{W_{l}}{\delta}
$$

where $W_{\ell}$, the equivalent width of a line, may be calculated numerically from

$$
\mathrm{W}_{\ell}=\int_{-\infty}^{+\infty}\left(1-\exp -\int \frac{\sigma}{\pi} \frac{a}{a^{2}+\left(\nu-\nu_{0}\right)^{2}} \mathrm{dm}\right) \mathrm{d} \nu
$$

Here

$a$ is Lorenz half width

$\nu_{0}$ the frequency at the center of the line.

Plass (1958) has shown that one can match this statistical model of the transmission function having uniform line intensity with a statistical model 
having an exponential intensity distribution for lines. From such a method of matching the two types of statistical band models we arrive at the following transmission function for the $9.6 \mu$ ozone band.

$$
\begin{aligned}
& \frac{\sinh \mathrm{k}_{\nu}{ }^{1 / 2} \mathrm{X}_{\nu}{ }^{\prime}}{\mathrm{k}_{\nu}{ }^{1 / 2} \mathrm{X}_{\nu}{ }^{\prime}} \text { when } \quad \mathrm{k}_{\nu}>0 \\
& \tau_{\nu}=\exp -\left[\mathrm{X}_{\nu}{ }^{\prime}\right] \times \\
& \frac{\sin \left|\mathrm{k}_{\nu}\right|^{1 / 2} \mathrm{x}_{\nu}^{\prime}}{\left|\mathrm{k}_{\nu}\right|^{1 / 2} \mathrm{X}_{\nu}^{\prime}} \text { when } \quad \mathrm{k}_{\nu}<0
\end{aligned}
$$

where

$$
\mathrm{x}_{\nu}^{\prime}=\frac{\pi}{4} \frac{\mathrm{W}_{\ell}}{\delta}
$$

and the other symbols have the same meaning as before.

\section{DISCUSSION OF RESULTS}

The main objective of this study is to examine the feasibility of determining atmospheric ozone. Since we do not at present have spectra taken at more than one station it has been necessary to calculate emission spectra from several known simultaneous soundings of ozone, temperature and dew point temperature, and then to invert such synthetic spectra to get back the ozone distributions. We have done this with the help of the atmospheric data presented in 'ozone sonde observations over North America' by Hering and Borden (1965). Three such inversions are shown in Figs. 3,4 and 5. The temperature and ozone datil were extrapolated to $50 \mathrm{~km}$ height. 
Two spectral intervals, $5 \mathrm{~cm}^{-1}$ wide, centered at $1000 \mathrm{~cm}^{-1}$ and $1050 \mathrm{~cm}^{-1}$ are used in the inversion scheme. These spectral intervals are chosen such that one of them at $1000 \mathrm{~cm}^{-1}$ has moderate ozone absorption while the other at $1050 \mathrm{~cm}^{-1}$ has strong absorption.

A comparison of the computed and observed distribution of ozone at Beford (Fig. 3) shows the ability of the computed curve to approximate smoothly the observed one. Although the computed curve can't reproduce the double maximum it succeeds in predicting the total ozone with $2 \%$ accuracy. This is so on account of the extremely small convergence level, $0.1 \%$, achieved in matching the radiance computed from observed and calculated ozone curves. In Fig. 4 we see the solution obtained for an ozone sounding at Fairbanks. Although the observed ozone profile in this case is not as complicated as the one shown for Bedford, the calculated total ozone is off by $5 \%$. This is primarily because of the $1 \%$ convergence level to which the radiances were matched. The computed spectrum for each case is shown in the respective figures. The $9.6 \mu$ band in the se two cases stands out quite significantly as there is a good amount of stratification in the temperature. To emphasize this aspect we show in Fig. 5 a case study for an Arctic Station, Thule, Greenland, where the temperature stratification is very weak resulting in almost a black body continuum for the spectrum. The inverted ozone profile, calculated with such a weak spectrum, shows a poor agreement with the observed profile. The computed total ozone is in error by $50 \%$. 
The observed spectrum at Palestine, Texas, offers a means to test the inversion scheme. So an attempt was made to invert the observed radiances in the 9.6 region of the spectrum and obtain an ozone distribution. This attempt was not successful on account of two important reasons. The meteorological data needed for inversion, namely the temperature and dew point temperature soundings at Palestine were not available. So it was necessary to use such data from a neighboring meteorological station, Shreveport. Secondly the absorption coefficients adopted for water vapor and ozone, although reasonable, are not exact. It is very important to have accurate measurements of the absorption coefficients in order to have a successful inversion scheme. So as an alternative to a rigorous inversion we have attempted to match the observed Palestine spectrum with the help of the Shreveport soundings and an ozone profile characteristic of the tropies shown in Fig. 6. The observed and computed spectra are compared in Fig. 7.

At this point it is desirable to examine the question concerning the number of independent pieces of information about atmospheric ozone that one can possibly elicit out of the emission spectrum in the $9.6 \mu$ region. This may be demonstrated from the nature of the weighting functions. In Fig. 8 we show, for the case of Fairbanks, the weighting functions $\mathrm{d} \tau / \mathrm{dz}$ for ozone, in the two spectral regions, of $5 \mathrm{~cm}^{-1}$ width, centered at 1000 and $1050 \mathrm{~cm}^{-1}$. The weighting functions resemble one another and essentially have the shape of the ozone profile. This is so on account of the weak absorption in the $9.6 \mu$ region. Even in the interval at 
$1050 \mathrm{~cm}^{-1}$, near the center of the absorption band, the ground is 'visible' and a significant part of the ground emission is transmitted to the top of the atmosphere. From the strong similarity of the two weighting functions we may infer that they cannot convey substantially different information about the ozone distribution. Nevertheless a small amount of dissimilarity that is present in the two weighting functions makes the information content of the two spectral intervals to some extent independent of one another. This is the reason for limiting ourselves to two independent parameters. An attempt to get three pieces of information with three spectral intervals resulted in a failure.

Let us now examine the practicability of determining the atmospheric ozone indirectly from measured radiance in the 9.6 $\mu$ region. As there are in practice some errors present in the measured radiance, we have to examine the degree to which the deduced solution will be influenced by such errors. For this purpose we have made an analysis of the error introduced in the total ozone due to a known error in radiance.

Let the total ozone be denoted by $\left[\mathrm{O}_{3}\right]$ and a small error in it by $\delta\left[\mathrm{O}_{3}\right]$. Similarly let I and $\delta \mathrm{I}$ be the corresponding intensity and an error in it. Now since both the total ozone and intensity are functions of the two parameters $Z_{\mathrm{m}}$ and h we scek to get

$$
\left(\frac{\triangle \log \left[\mathrm{O}_{3}\right]}{\wedge \log Z_{\mathrm{m}}} / \frac{\Delta \log \mathrm{I}}{\triangle \log Z_{\mathrm{m}}}\right)_{\mathrm{h}}
$$


which gives an amplification of the error in total ozone due to an error in intensity when $\mathrm{h}$ is held constant. In an analogous way we can get

$$
\left(\frac{\Delta \log \left[\mathrm{O}_{3}\right]}{\Delta \log \mathrm{h}} / \frac{\Delta \log \mathrm{I}}{\Delta \log h}\right)_{z_{m}}
$$

the amplification of error when $Z_{m}$ is a constant. With the help of the four cases presented in Figs. 3 to 6 we have obtained these amplifications and they are tabulated for each case and the two wavelengths in Table 1 . We find from this study there is generally an amplification of the error. An error of $1 \%$ in the measured radiance may result in an error of $5 \%$ in the derived total ozone. In the particular case of Thule, where the atmosphere is close to isothermal condition, the amplification of error is enormous and no meaningful information on ozone could be extracted.

The above analysis did not consider the errors introduced by the assumptions made in arriving at a model for the ozone distribution. The assumption of photochemical equilibrium above some high altitude, $30 \mathrm{~km}$, and the height of the level separating the stratospheric and trophospheric ozone should be examined. From Fig. 8 where the weighting functions are shown we see that as much as $20 \%$ of atmospheric emission could come from the region above $30 \mathrm{~km}$ and about $10 \%$ from the troposphere. By assuming photochemical equilibrit.m above $35 \mathrm{~km}$ we may be able to reduce the emission of the top layer by hall. Even then small crors arising from these assumptions will be marnified in the solution obtilined, as shown earlier. 
There can be errors introduced from the incorrect temperature and dew point temperature soundings. Since about $50 \%$ of the emission from the ground is transmitted to the top we need to know the ground temperature and emissivity quite accurately.

From the foregoing study we can arrive at the following conclusions. At the stations where radiosonde data are available total ozone could be estimated to about 10 to $20 \%$ accuracy provided the satellite measured radiance is accurate to $1 \%$ in the $9.6 \mu$ region. Although the accuracy of the indirect determination is poor we may hope to get at least a crude picture of the day to day variation of total ozone over the mid latitudes where 10 to $20 \%$ changes in total ozone occur. The indirect ozone determination may be improved by improving the spectral resolution of the radiance measured.

\section{ACKNOWLEDGMENTS}

It is a pleasure to thank my colleagues Drs. B.J. Conrath, E. J. Williamson and V. Kunde for helpful discussion. I am grateful to Dr. R. Hanel for his encouragement all along this study. 


\section{REFERENC ES}

Conrath, B. J. (1968), "Inverse Problems in Radiative Transfer: A Review," Proc. of the Astronautical Congress, Ed. by Michal Lunc, Pergamon Press, 1968.

Dave, J. V., P. A. Sheppard and C. D. Walshaw (1963), "ozone distribution and the continuum from observations in the region of the $1043 \mathrm{~cm}^{-1}$ band." Quar. Journal of Roy. Meteor. Soc., Vol. 89 (381), pp. 307-318.

Dütsch, H. U. (1966), "Two years of Regular Ozone Soundings over Boulder, Colorado," National Center for Atmospheric Research - Technical Report, NCAR - TN - 10

Elsasser, W. M., with M. Culbertson (1960), Atmospheric radiation Tables. Met. Mon. Vol. 4. No. 23., Amer. Met. Society, Boston, Mass.

Goody, R. M. $(1964$, a). "Atmospheric Radiation I, Theoretical Basis." Oxford University Press.

Goody, R. M. $(1964, \mathrm{~b})$. "The transmission of radiation through inhomogeneous atmosphere." Jour. Atmos. Sci., Vol. 21, pp. 575-581.

Hering, W. S. and T. R. Borden, Jr. $(1965$, a), "Mean distribution of ozone density over North America, 1963 - 1964." Air Force Cambridge Research Laboratories AFCRL - 65 - 913, Environmental research papers, No. 162.

Hering, W. S. and T. R. Borden, Jr. $(1965$, b), "Ozone sonde observations over North America, Vol. 3." Air Force Cambridge Research Laboratories AFCRL - 64 - 30 (111), Environmental Research paper, No. 133. 
Hitschfeld, W. and J. T. Houghton (1961), "Radiative Transfer in the lower stratosphere due to $9.6 \mu$ band of ozone," Q. J. Roy. Met. Soc., Vol. 87, pp. $562-577$.

Möller, F. and E. Raschke (1963), "Evaluation of Tiros III radiation data," Interim report No - 1, NASA Research Grant Ns G-305.

Plass, G. N. (1958), "Models for spectral band absorption." Jour. Opt. Soc. of America. Vol. 48, pp. 690-703.

Walshaw, C. D. (1954), "An Experimental investigation of the $9.6 \mu$ band of ozone," Dissertation submitted for the degree of doctor of philosophy at Cambridge University • p. 102.

Walshaw, C. D. and C. D. Rodgers (1963), "The effect of Curtiss-Godson approximation on the accuracy of radiative heating rate calculation," Q.J.R. Met. Soc., Vol. 89 , pp. 122-130.

Walshaw, C. D. (1957), "Integrated absorption by the $9.6 \mu$ band of ozone," Quar. J. R. Met. Soc., Vol。83, pp. 315-321.

Wark, D. Q. and H. E. Fleming, 1966, "Indirect measurements of Atmospheric Temperature profiles from satellites: 1. Introduction," Monthly Weather Review, Vol. 94, pp. 351-362. 
Table 1

Amplification of Error

\begin{tabular}{cccc}
\hline & & $\frac{\partial \log \left[\mathrm{O}_{3}\right]}{\partial \log \mathrm{Z}_{\mathrm{m}}} \cdot \frac{\partial \log \mathrm{Z}_{\mathrm{m}}}{\partial \log \mathrm{I}}$ & $\frac{\partial \log \left[\mathrm{O}_{3}\right]}{\partial \log \mathrm{h}} \cdot \frac{\partial \operatorname{logh}}{\partial \log \mathrm{I}}$ \\
\hline FAIRBANKS & $\mathrm{I}_{1}$ & -3.1 & -4.9 \\
& $\mathrm{I}_{2}$ & -2.0 & -5.2 \\
BEDFORD & $\mathrm{I}_{1}$ & -3.7 & -3.3 \\
& $\mathrm{I}_{2}$ & -2.6 & -105.0 \\
THULE & $\mathrm{I}_{1}$ & -34.5 & +104.6 \\
& $\mathrm{I}_{2}$ & -158.0 & +2.96 \\
SIMULATION & $\mathrm{I}_{1}$ & -4.3 & +0.4 \\
\hline
\end{tabular}




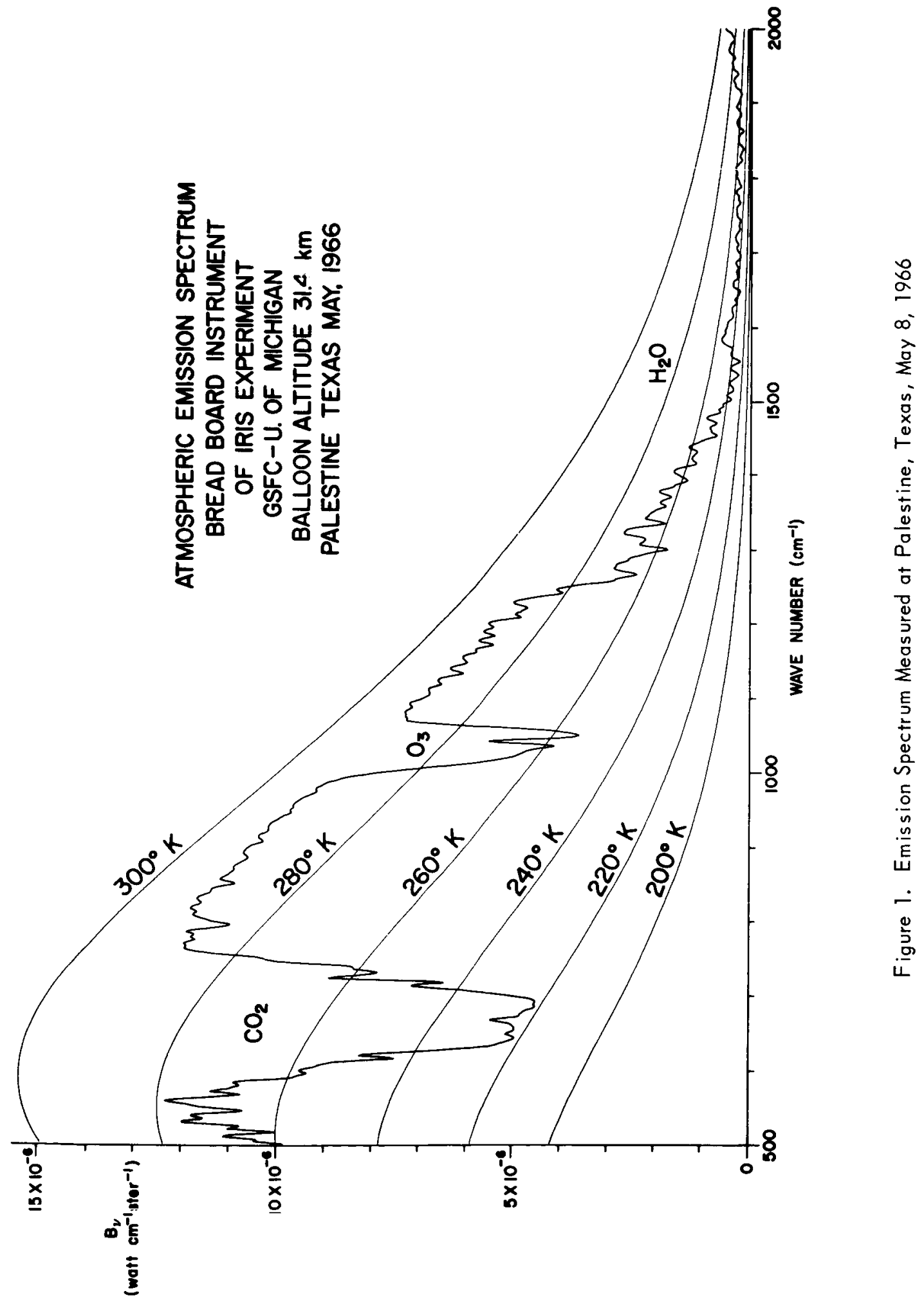




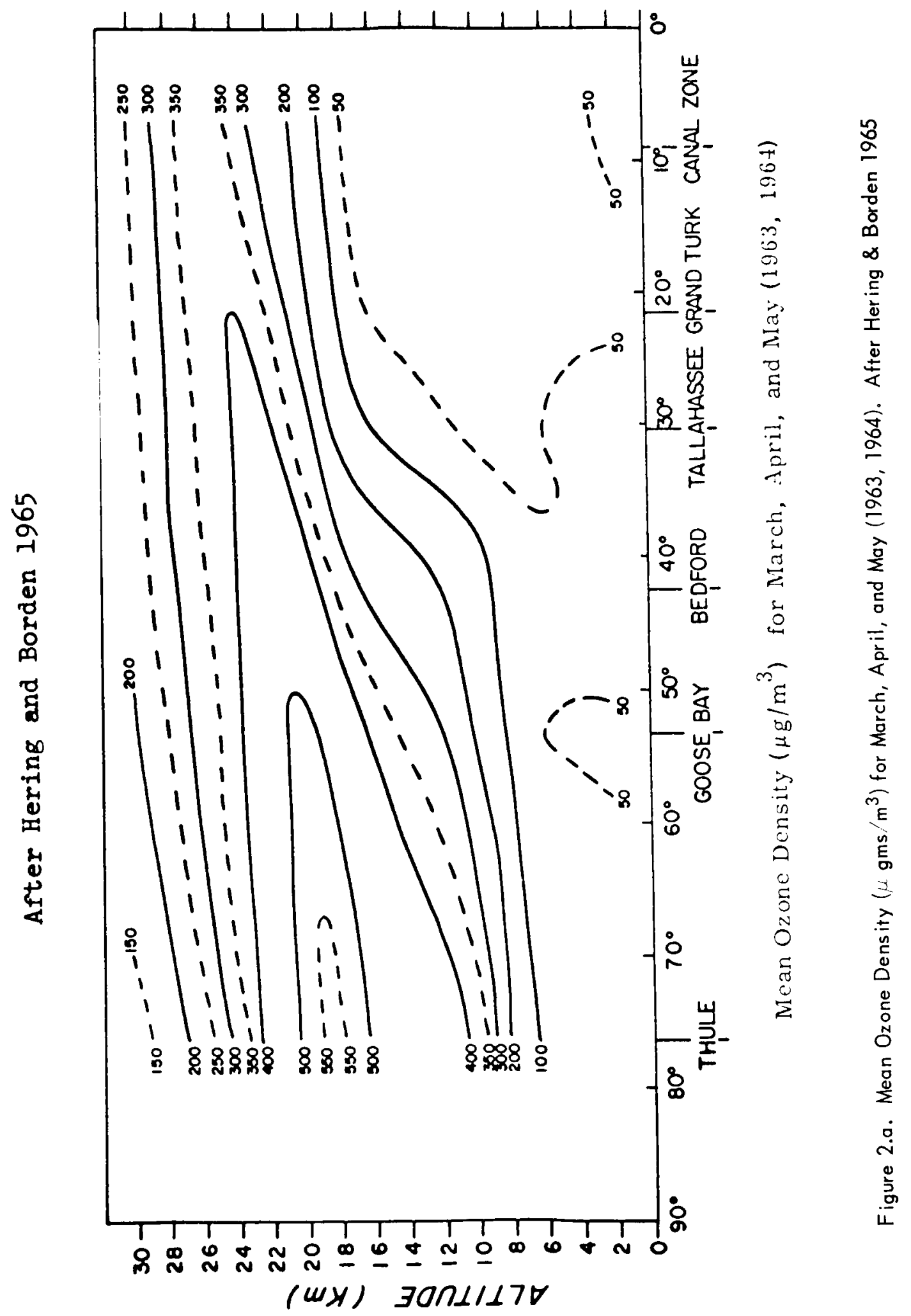




\section{LEGENDS TO FIGURES}

Fig. 1. Emission spectrum measured at Palestine, Texas, May 8, 1966.

Fig. 2.a. Mean ozone density $\left(\mu \mathrm{gms} / \mathrm{m}^{3}\right)$ for March, April, and May (1963, 1964). After Hering \& Borden 1965.

b. Mean ozone density $\left(\mu \mathrm{gms} / \mathrm{m}^{3}\right)$ for September, October, and November (1963, 1964). After Hering \& Borden 1965.

Fig. 3. Case Study: Bedford, Feb. 20, 1964.

Fig. 4. Case Study: Fairbanks, June 24, 1964.

Fig. 5. Case Study: Thule, March 25, 1964.

Fig. 6. Emission spectrum calculated to match the spectrum obtained at Palestine on May 8, 1966.

Fig. 7. Comparison of the Palestine emission spectrum in the $9.6 \mu$ region with the calculated spectrum shown in Fig. 6 .

Fig. 8. Weighting functions for ozone calculated for the case of Fairbanks, Alaska. 


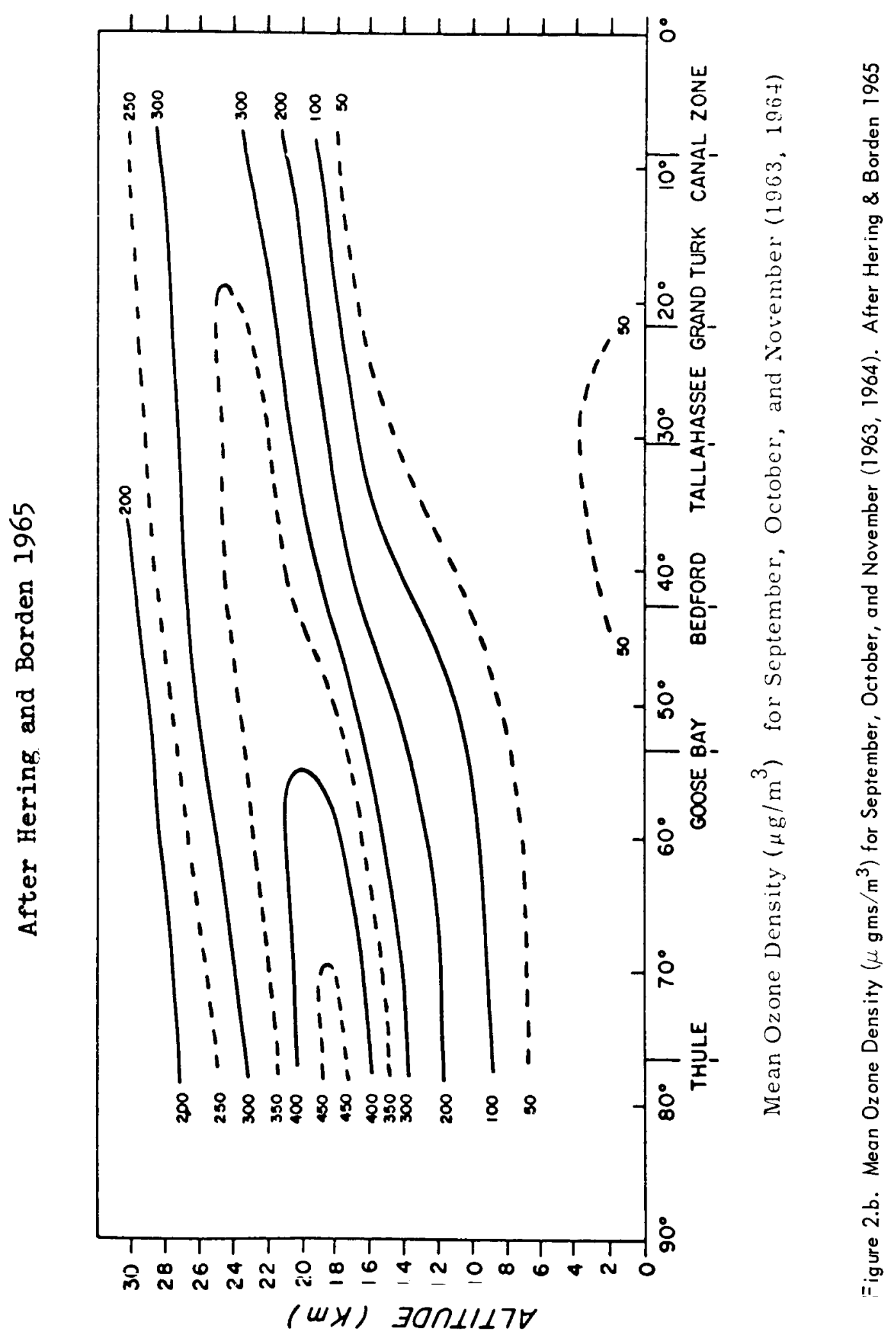

PAGE NUMbers ${ }^{21}$ From HERE

TO END OF DOC ARE DIFFERENT 


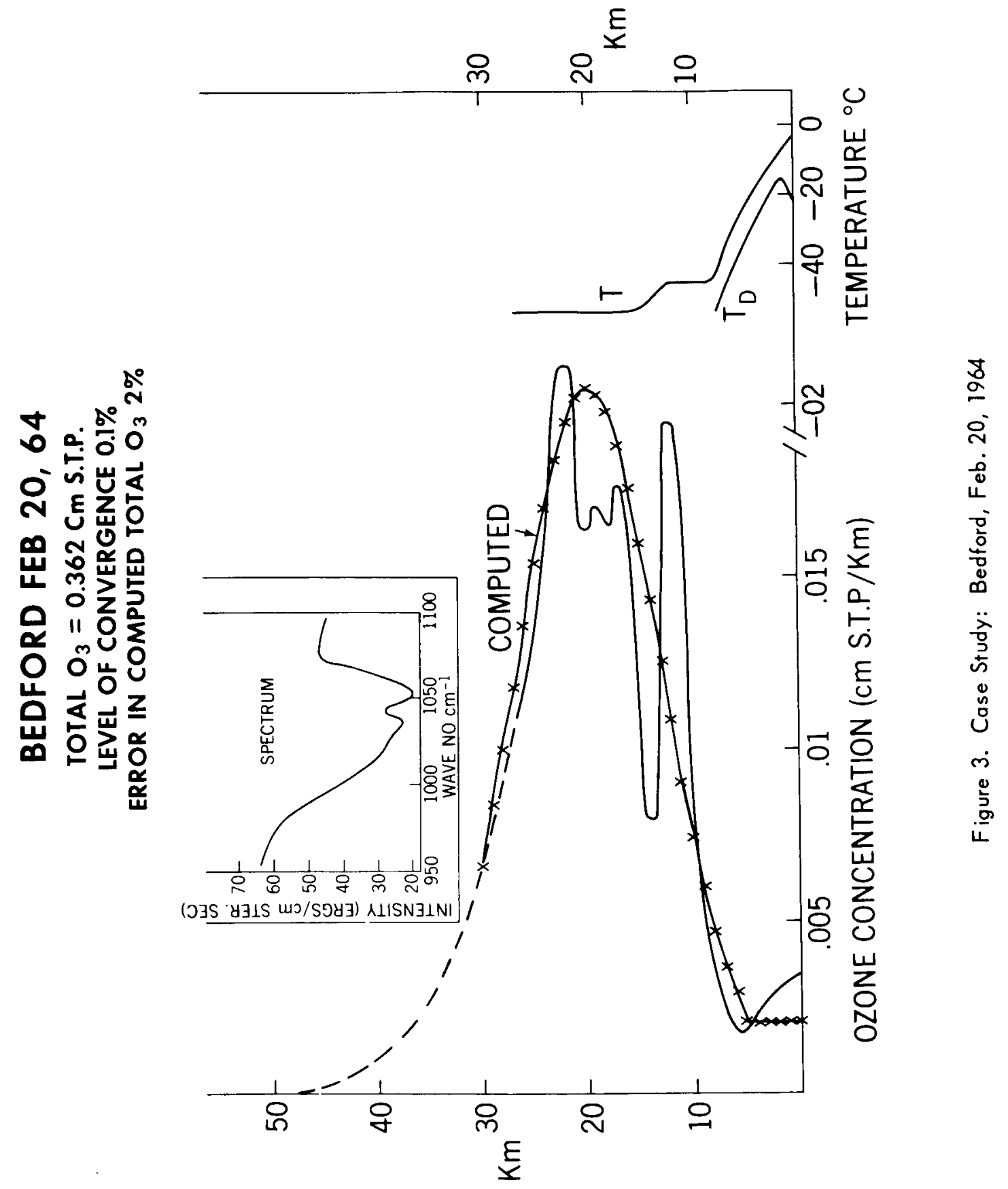




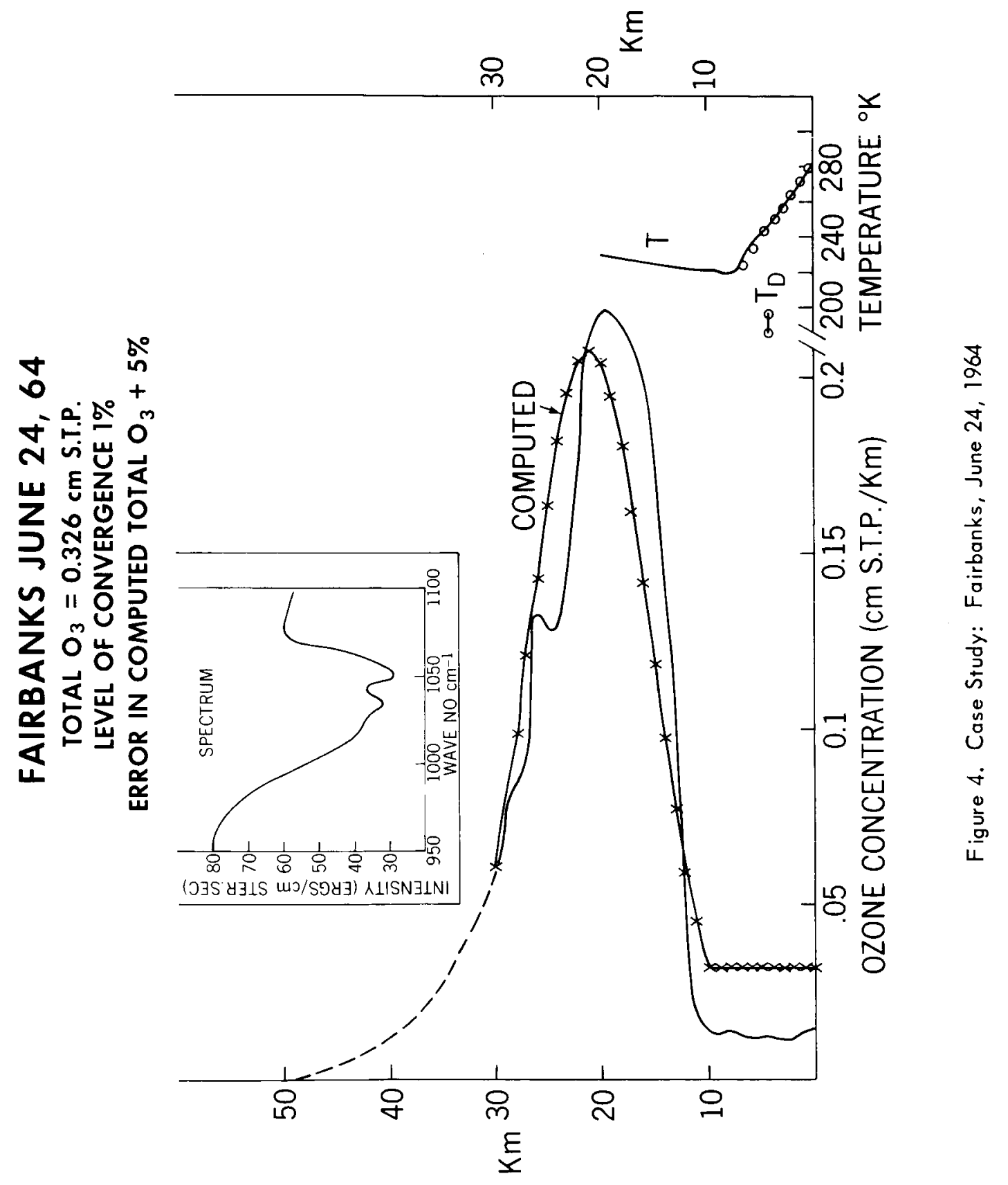




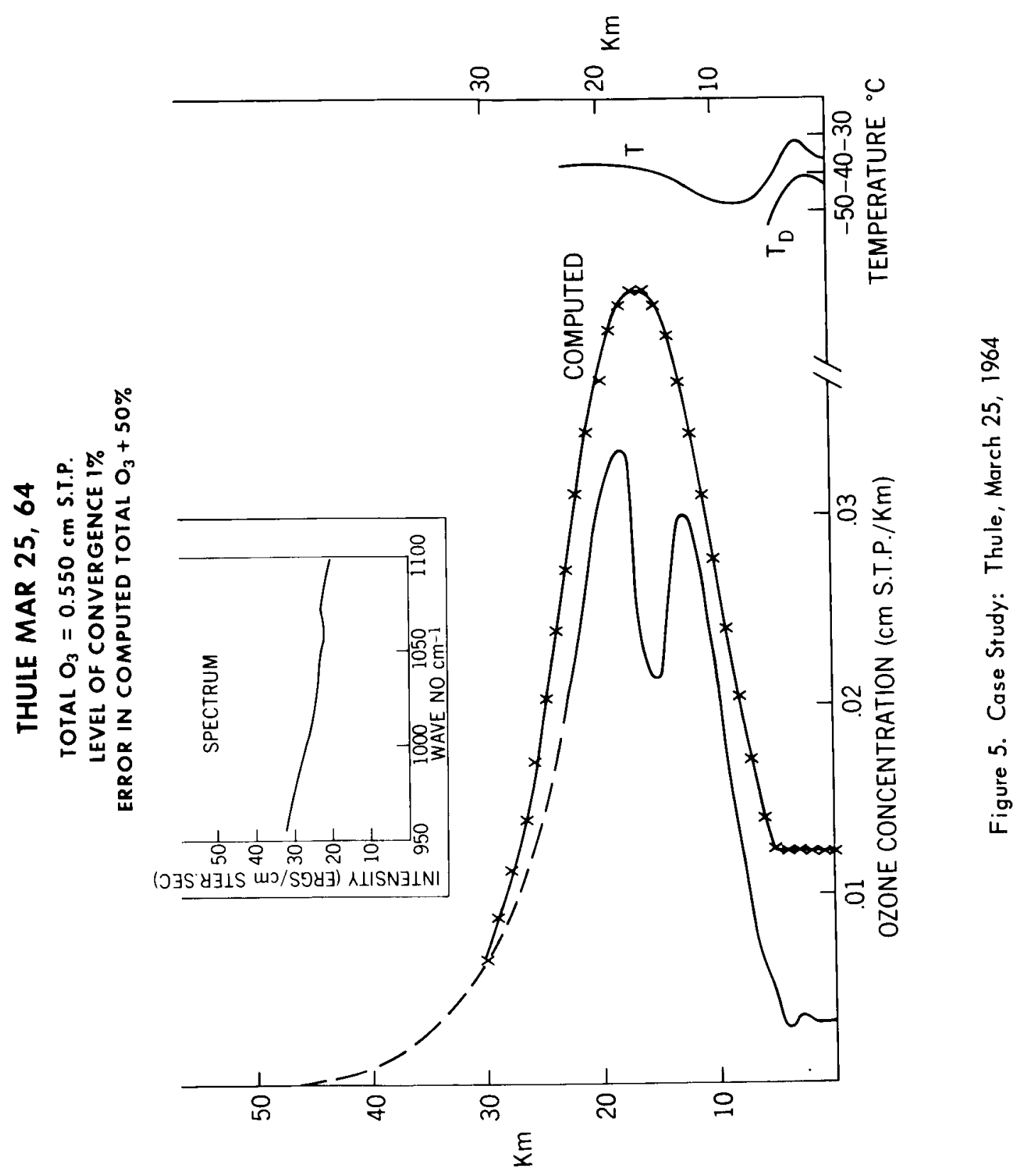




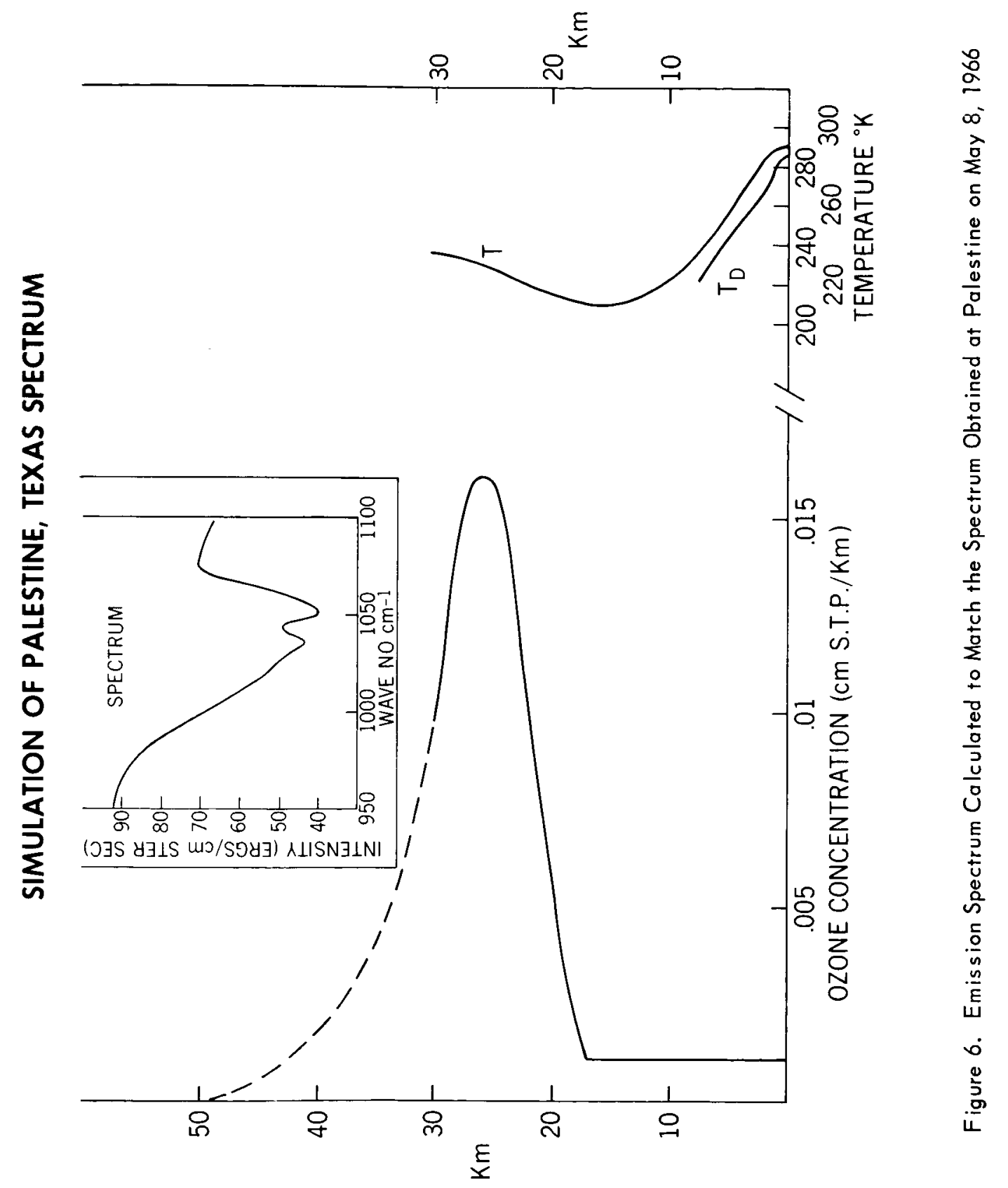




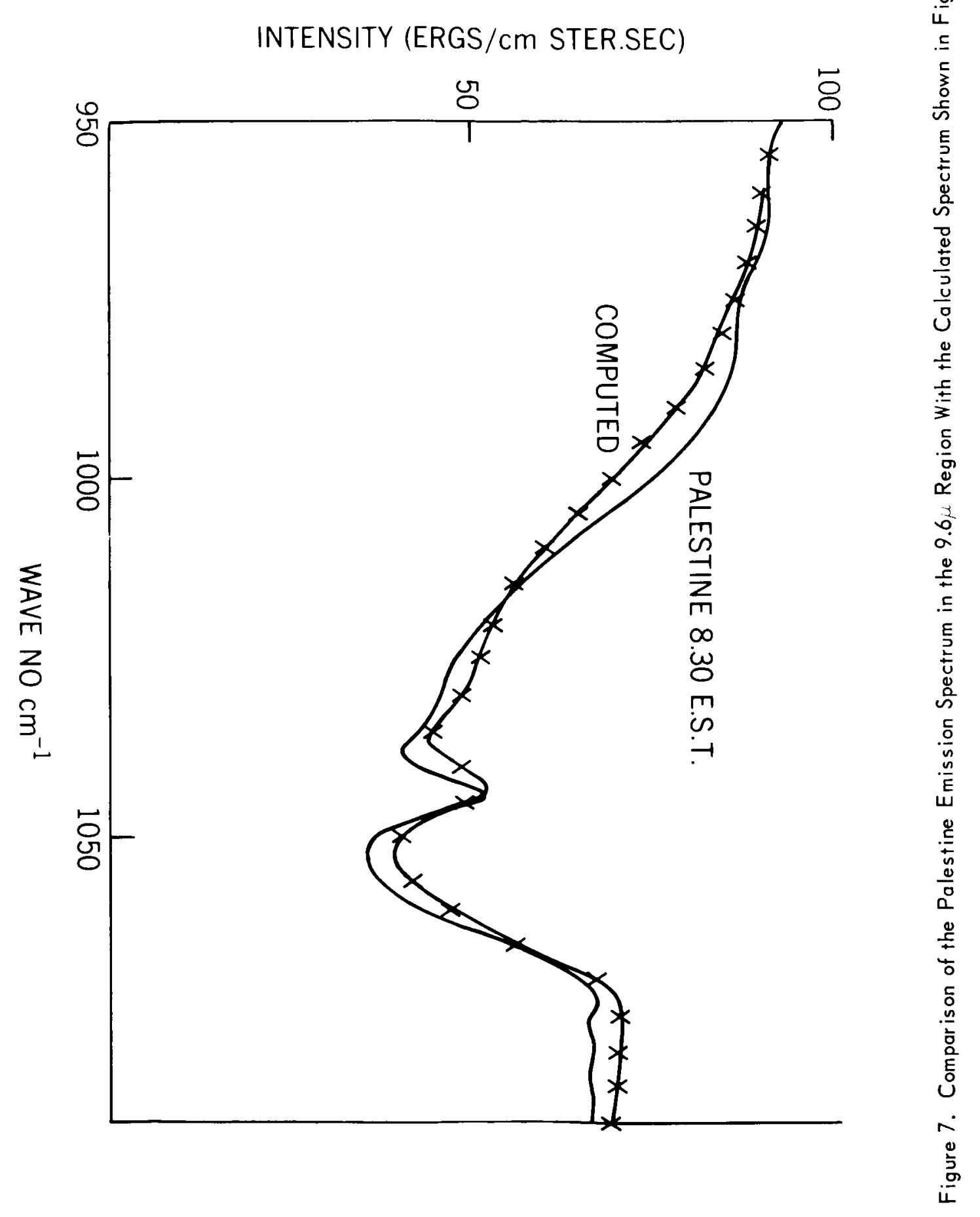




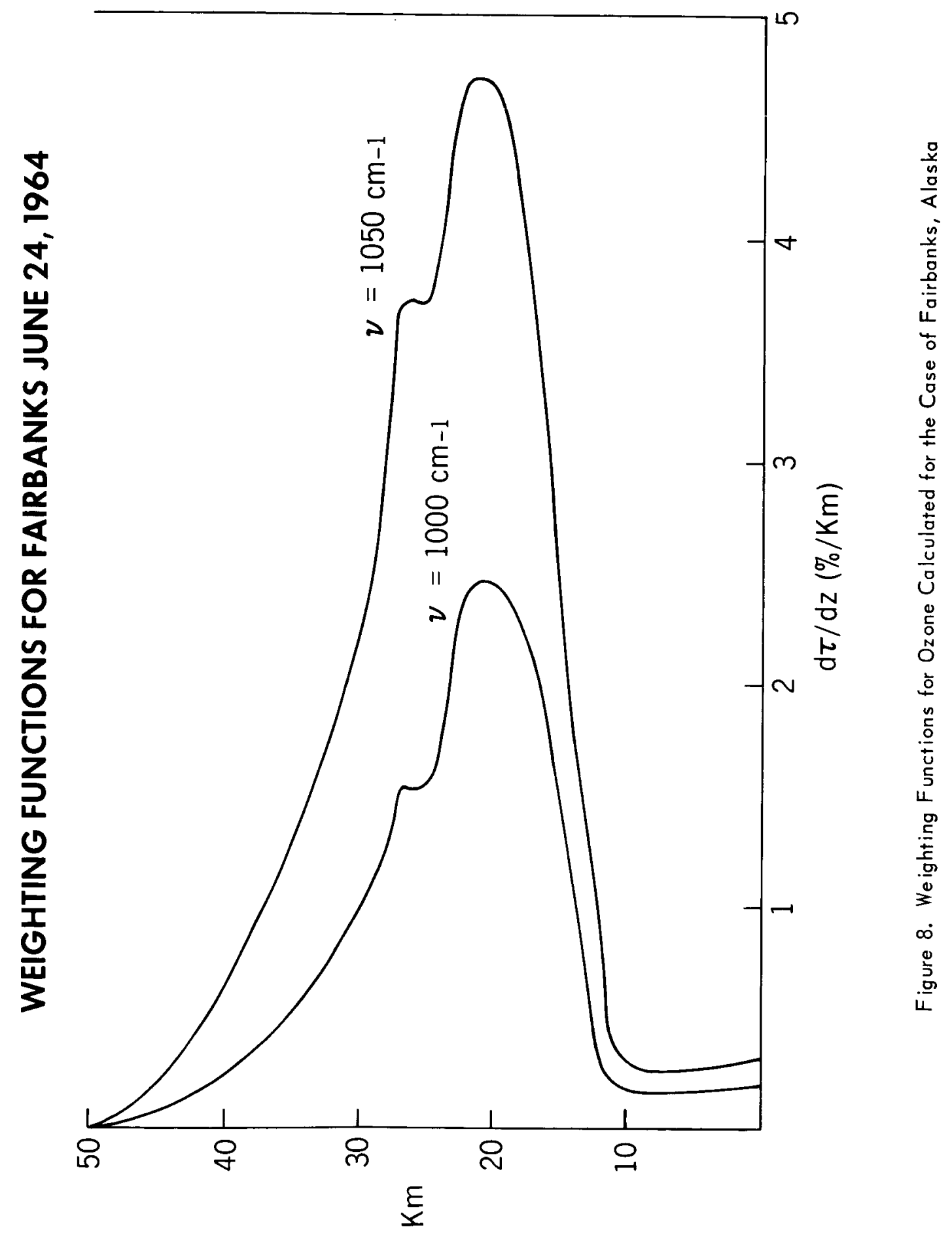

